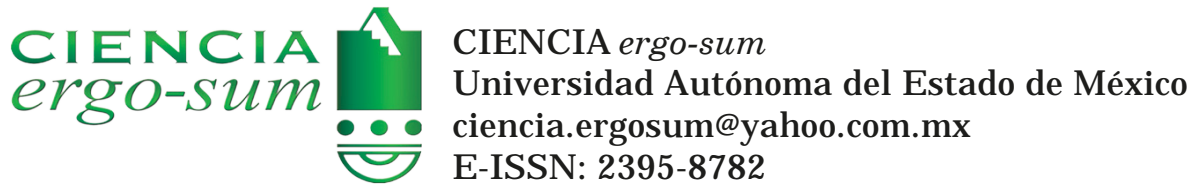

\title{
Las candidaturas independientes: retos jurídicos para fortalecer la democracia en México en el futuro inmediato
}

\section{Ordóñez, J oaquín}

Las candidaturas independientes: retos jurídicos para fortalecer la democracia en México en el futuro inmediato CIENCIA ergo-sum, vol. 28, núm. 1, marzo-junio 2021 |e108

Universidad Autónoma del Estado de México, México

Esta obra está bajo una Licencia Creative Commons Atribución-NoComercial-SinDerivar 4.0 Internacional .

Ordóñez, J . (2020). Las candidaturas independientes: retos jurídicos para fortalecer la democracia en México en el futuro inmediato. CIENCIA ergo-sum, 28(1). https://doi.org/10.30878/ces.v28n1a2 


\title{
Las candidaturas independientes: retos jurídicos para fortalecer la democracia en México en el futuro inmediato
}

\section{Independent candidates: Unavoidable challenges to strengthen democracy in Mexico in the immediate future}

\author{
Joaquin Ordóñez \\ Universidad Autónoma del Estado de México, México \\ joaquin.o@me.com \\ (1) http://orcid.org/0000-0002-6447-7188
}

Recepción: 14 de septiembre de 2018

Aprobación: 25 de marzo de 2019

\begin{abstract}
RESUMEN
Se analizan los obstáculos jurídicos que enfrenta la nueva figura electoral apartidista de las candidaturas independientes en contraste con la necesidad urgente de fortalecer la democracia en México. La metodología empleada fue con base en diversos datos bibliográficos y estadísticos sobre el caso mexicano. A manera de conclusión, se plantean ocho medidas para superar esos retos y fortalecer la democracia que se vive cotidianamente en los procesos electorales.
\end{abstract}

PALABRAS ClaVE: candidaturas independientes, democracia, elecciones.

\begin{abstract}
The objective of this article is to analyze the legal obstacles faced by the new nonpartisan electoral figure of independent candidacies in contrast to the urgent need to strengthen democracy in Mexico. The methodology used was based on various bibliographic and statistical data on the Mexican case. As a conclusion, eight measures are proposed to overcome these challenges and strengthen the democracy that is experienced daily in electoral processes.
\end{abstract}

KEYWORDS: Independent candidacies, democracy, elections.

\section{INTRODUCCIÓN}

El estado democrático liberal tiene como característica la libre competencia por el poder, lo cual implica la realización periódica de elecciones libres, abiertas, pacíficas y disputadas entre los electores y entre las diferentes opciones políticas (Schumpeter, 1996). En ese sentido, el sistema jurídico en México ha incluido en fechas recientes $\left[{ }^{[}\right]$la figura del candidato independiente, después de varias controversias surgidas con motivo de la falta de regulación de dicha figura, ${ }^{[2]}$ lo que también marcó la pauta para que fuera considerado como una partidocracia, pues solamente los partidos políticos constituidos podían intervenir de manera formal en los asuntos políticos del país, pues se han ido transformando: pasar de ser entidades canalizadoras de las demandas sociales hacia el gobierno e instrumentos para la participación de las personas en la cosa pública a estructuras de oligarquía concentradoras del poder público poniendo en duda su naturaleza democrática (Michels, 2008). Por ello, incluso, hay quien considera que México ha sido el ejemplo perfecto de un Estado con un régimen autoritario de partido dominante, [3] el cual consiste en "el control, tanto del poder ejecutivo como del legislativo, de manera continua por un solo partido durante al menos 20 años o, al menos, cuatro elecciones consecutivas" (Greene, 2007: 12).

Aproximadamente, 80 años el Partido Revolucionario Institucional (PRI) dominó el panorama electoral y ocupó la mayoría de los cargos públicos tanto federales como estatales, e incluso municipales, salvo en 
recientes años en los que ha tenido una decadencia causada por la insatisfacción creciente de los votantes como consecuencia de las crisis económicas y de los agudos problemas de delincuencia y otros fenómenos sociales. Ese dominio del PRI fue gracias a varios factores, entre los cuales se encuentran muchas ventajas de carácter institucional sustentadas en el aspecto jurídico (Constitución y leyes), ya que se establecían reglas para la competencia electoral que ponían obstáculos y límites a la competitividad de los demás partidos. ${ }^{[4]}$ Tales límites aún siguen persistiendo, aunque en menor medida respecto a los partidos políticos, pero con cierta intensidad para el caso de la figura de las candidaturas independientes, que es de creación reciente. En los últimos años ha aumentado la competencia electoral debido, en gran parte, a la madurez de la ciudadanía, al aumento en la solidez de las instituciones encargadas de ello, a la intervención de las redes sociales como un factor para transparentar las acciones del gobierno y de los partidos políticos, pero sobre todo al hartazgo de la ciudadanía en aspectos como la economía y la delincuencia. Lo anterior ha traído como resultado que se haya implementado la regulación para las candidaturas independientes debido principalmente a la presión política y a los fenómenos de candidatos independientes que, en una época en la que no estaba regulada esa figura, provocó que organismos internacionales emitieran criterios que a la larga presionaron para establecerla.

Sin embargo, como se verá más adelante, tales candidaturas independientes ${ }^{[5]}$ tienen delante varios retos por superar; la mayoría de ellos gracias a que dicha regulación, lejos de procurar e incentivar a que los ciudadanos se postulen a cargos de elección popular, los desalienta y obstaculiza. El caso mexicano en cuanto a las candidaturas independientes ha tenido altibajos, pero no es sino hasta 2018 cuando por primera vez las boletas electorales incluyeron a ciudadanos postulados de manera independiente para cargos federales (diputaciones federales, senadurías y presidencia de la República). ${ }^{[6]}$ La particularidad de esos candidatos es que surgen directamente de organizaciones partidistas: Margarita Zavala militaba en el Partido Acción Nacional (PAN), Jaime Heliodoro Rodríguez Calderón, el Bronco, en el PRI antes de que se postulara -y ganara- la elección de gobernador en Nuevo León, y Armando Ríos Piter en el Partido de la Revolución Democrática (PRD); todos ellos ya habían ocupado cargos de elección popular gracias a la postulación de sus respectivos partidos políticos, lo que significa que la experiencia y el prestigio ganado bajo el auspicio de un partido les permitieron postularse como independientes.

Las candidaturas independientes son figuras jurídicas y políticas propias de los regímenes políticos democráticos, los cuales son opuestos a los regímenes dictatoriales, ${ }^{[7]}$ y están relacionadas con el sistema democrático representativo en el que el pueblo tiene (debe tener) la posibilidad de intervenir en las decisiones públicas. ${ }^{8}$ ] Por tanto, el candidato independiente es un actor político, es decir, de acuerdo con la doctrina (Lizcano Fernández, 2012), es una persona facultada dentro de una determinada colectividad para tomar decisiones vinculantes como autoridad (individuo especializado en la toma de esas decisiones) y que además es un representante designado democráticamente, en contraposición a las autoridades "autoritarias" que acceden al poder gracias a medios no democráticos. Asimismo, el fenómeno de las candidaturas independientes en el siglo XXI, no nada más en México sino en el mundo, está relacionado con la crisis del modelo de partidos cartel,[9] ya que los ciudadanos comienzan a mirar hacia una posible postulación sin depender de los partidos como consecuencia del debilitamiento de esas organizaciones. También es importante el fenómeno de las redes sociales porque ha transformado la forma de hacer campaña en el ámbito internacional, ya que, en ese sentido, ha habido un proceso de cambio donde las modernas tácticas y estrategias de campaña que se realizan a través de los medios masivos de comunicación, así como de internet y las llamadas tecnologías de información y comunicación (TIC), han dejado casi obsoletas a las prácticas que por tradición se venían ejecutando (preponderantemente basadas en el contacto directo o más directo con los ciudadanos electores), fenómeno que influye de forma determinante en las candidaturas independientes al no ser necesario invertir en grandes gastos por concepto de difusión de la imagen, lo cual tiende a equilibrar la competencia entre los candidatos independientes y los partidistas (Heras Gómez y Díaz Jiménez, 2017). 
También la doctrina ha considerado que existe una relación entre el carácter equitativo o justo de las reformas electorales con el grado de competitividad que se desarrolla en las elecciones (Méndez de Hoyos, 2006), lo cual hace pensar que con cada reforma se ha impulsado esa equidad y justicia; sin embargo, para el caso de las candidaturas independientes, el logro está solamente en su institucionalización y no en el establecimiento de las reglas suficientes para que tengan un impacto significativo en la configuración gubernamental mexicana. Por ello, no obstante que la Constitución Política ya permite postularse sin partido político, los requisitos legales ${ }^{[10]}$ parecen obstaculizar su efectiva aplicación. Por tanto, si se pretende fortalecer la democracia mexicana, así como la equidad y justicia en sus procesos de elección, se deben superar algunos de esos obstáculos, lo cual representa remontar algunos retos inevitables como el cumplimiento de los requisitos constitucionales, darse a conocer en una sociedad partidista y, al final, transformar el paradigma democrático mexicano.

\section{Cumplir con los reQuisitos constitucionales y Legales}

El actual Estado de derecho mexicano está inmerso en un sistema jurídico en el que se aplica de manera jerárquica la norma jurídica, es decir, desde la Constitución Política de los Estados Unidos Mexicanos, las leyes federales, las constituciones y leyes locales hasta llegar a las normas individualizadas que por lo general se expresan en sentencias o resoluciones de los órganos jurisdiccionales. Un sistema jurídico implica el respeto y cumplimiento de las normas establecidas institucionalmente, es decir, aquellas que son producto de la actividad legislativa en el seno de un órgano estatal cuya función primordial es la creación de normas. Tal respeto a las normas jurídicas tiene una doble vertiente: por un lado, está la obligación del órgano de gobierno encargado de crear y poner en vigencia esas normas bajo un procedimiento establecido en específico y, por el otro lado, el deber de los destinatarios de esa norma (que pueden ser también los creadores de ésta) de acatar y cumplir su contenido. En ese sistema jurídico también se incluyen los procesos de renovación de los integrantes gubernamentales y las normas jurídicas (pertenecientes al sistema que regula esos procesos), los cuales son objeto de respeto y cumplimiento por parte de todos aquellos que se encuentren inmersos en los supuestos establecidos por la misma norma jurídica.

Así, desde la Constitución Política Federal[11] hasta las normas individualizadas, ${ }^{[12]}$ son el fundamento de esos procesos de elección democrática, ${ }^{[13]}$ ya que la Constitución establece los lineamientos fundamentales, entre los cuales se encuentran los requisitos para que los ciudadanos puedan aspirar a cargos de elección popular sin que sea necesario que algún partido político los postule. De esta manera, en México se prevé que el derecho que los ciudadanos tienen de solicitar su registro de manera independiente se deberá sujetar a los requisitos, condiciones y términos establecidos legalmente, e incluye un proceso de selección de candidatos independientes que a su vez comprende las siguientes etapas: $a$ ) convocatoria, $b$ ) actos previos al registro, $c$ ) obtención del apoyo ciudadano y $d$ ) registro. Respecto a la etapa de obtención de apoyo al ciudadano, la legislación establece que los aspirantes a candidatos independientes para el cargo de presidente de la República contarán con 120 días para recabar el porcentaje de apoyo ciudadano requerido, y para ese cargo establece que la cédula de apoyo deberá contener cuando menos la firma de 1\% de los ciudadanos incluidos en la lista nominal de electores con corte al 31 de agosto del año previo al de la elección y también estar integrada por electores de por lo menos 17 entidades federativas que sumen al menos $1 \%$ de los ciudadanos incluidos en la lista nominal de electores en cada una de ellas (LEGIPE, 2014).

Esos requisitos son adicionales a los de elegibilidad que se establecen en general para ocupar los cargos de elección popular por ciudadanos postulados por un partido político y también de los documentos que se deben acompañar a la solicitud de registro (entre los cuales se incluye su plataforma electoral con las principales propuestas que sostendrá en campaña, los informes de gastos y egresos de los actos necesarios para obtener el apoyo ciudadano y la cédula de apoyo con los datos de las credenciales para votar con fotografía vigentes de cada uno de los ciudadanos que manifiestan el apoyo en el porcentaje mencionado). Lo referido a la cédula 
de apoyo es verificado por el Instituto Nacional Electoral (INE) en una segunda etapa, lo cual incluye, desde luego, constatar que no contenga datos falsos o erróneos que acompañen las copias de las respectivas credenciales para votar vigente y, en caso de que un mismo ciudadano haya dado el apoyo en más de una ocasión, computar nada más la primera. Al final, si el órgano verificador se percata de que no se reúne el porcentaje mínimo requerido de los apoyos ciudadanos, la solicitud de registro de candidatura independiente se tendrá por no presentada (LEGIPE, 2014).

Como se ve, los requisitos jurídicos establecidos para la obtención del registro como candidato independiente constituyen por sí mismos un obstáculo a superar por parte de los ciudadanos interesados en postularse a cargos de elección popular, ya que el número de los que deben integrar la cédula de apoyo son casi el mismo número de requeridos para la constitución de un partido político, aunque pequeño. En efecto, de acuerdo con la Ley General de Partidos Políticos (LGPP, 2014), la organización que pretenda constituirse como partido político nacional deberá contar con tres mil militantes en por lo menos veinte entidades federativas (60 000) o trescientos militantes en por lo menos doscientos distritos electorales uninominales $(60000)$ y agrega que bajo ninguna circunstancia el número total de sus militantes en el país podrá ser inferior a $0.26 \%$ del padrón electoral federal utilizado en la elección federal ordinaria inmediata anterior a la solicitud de registro. De acuerdo con las estadísticas del INE, en un corte del 16 de junio de 2017, la lista nominal[14] contaba con 85953712 ciudadanos, mientras que el padrón electoral[15] contaba con 87317602 ciudadanos. Estos números significan que al menos 227026 ciudadanos ( $0.26 \%$ de 87317602 ) deberán constituir la militancia de la organización que pretenda constituirse como nuevo partido político. En contraste, el número de firmas necesarias para reunir el requisito legal de los apoyos ciudadanos para el caso de la candidatura a la Presidencia de la República (en el proceso electoral federal del 2018) fue de 866 593, las cuales debieron estar distribuidas en por lo menos 17 entidades federativas que sumaran cuando menos $1 \%$ del total en las respectivas listas nominales. [16]

El resultado es que el número de apoyos ciudadanos para quien pretenda postularse como candidato independiente es mucho mayor que el número de militantes requeridos para formar un partido político, siendo la diferencia con los datos presentados de 639567 ciudadanos adicionales para el caso de la candidatura independiente. [17] Es decir, los requisitos no son proporcionales ni están diseñados con igualdad de condiciones e impiden a los ciudadanos que pretendan ser candidatos independientes lograr un registro por ser de difícil cumplimiento al implicar un consumo de recursos humanos y financieros excesivos en el intento por obtener los apoyos ciudadanos (a diferencia de los partidos políticos, cuya estructura organizacional y financiamiento les permiten llevar a cabo empresas de esa envergadura) y en algún momento participar en la vida democrática de México y contender en el proceso electoral.

\section{Darse a CONOCER EN UNA SOCIEDAD PARTIDISTA}

El cumplimiento de los requisitos constitucionales y legales es uno de los primeros pasos que se deben satisfacer para que los ciudadanos interesados en postularse como candidatos a cargos de elección popular lo puedan hacer prescindiendo de los partidos políticos, ya que también se enfrentan a la dificultad de darse a conocer en una sociedad partidista por tradición y que no cuenta con la educación cívica necesaria para considerar a los ciudadanos como candidatos independientes. Lo anterior trae como consecuencia el problema de darse a conocer en una sociedad muy mediatizada, aunque en el modelo de mediatización actual, en donde las redes sociales son un elemento importante en la transmisión de la información, esto ha dejado de ser gradualmente un problema, pero, aun así, los partidos políticos que cuentan con toda una estructura y un financiamiento, no sólo para la campaña sino para las actividades ordinarias, tienen una ventaja sensible frente a los candidatos independientes, ya que no cuentan con esa estructura y financiamiento. Es tan importante este aspecto que incluso hay casos en los que el uso de internet ha sido determinante para el éxito de una campaña electoral: 
Obama recaudó casi 750 millones de dólares en las dos campañas [...] 659 millones provenían de contribuciones individuales. La mayor parte se recaudó por medio de internet, esto tenía muchos beneficios; por ejemplo, que las donaciones no tienen que utilizarse para sufragar el aparato que las recauda y que la horizontalidad del modelo permitía adquirir menos compromisos (Espino-Sánchez, 2014: 49).

Esa horizontalidad es un aspecto que podría ser aprovechado por los candidatos independientes; sin embargo, la falta de una estructura (como la de los partidos políticos) provoca que esos candidatos y la escasa estructura humana que los apoya se vean imposibilitados para implementar alguna estrategia de recolección de fondos como en el ejemplo mencionado, además de que los límites [18] a los gastos de campaña son otro factor que lo obstaculiza. Por otro lado, el financiamiento no es el único aspecto (aunque es muy importante) en el que los candidatos independientes deben sustentar su actividad de campaña, ya que también está el aspecto político requerido para posicionarse en su momento en las preferencias del electorado, lo cual está soportado de forma preponderante en una opinión pública cuya actividad puede potencialmente incidir en la actividad del Estado al incorporar sus demandas; con esto se tendría la llamada democracia participativa en contraste con las democracias representativas que dependen de los medios de comunicación masiva (Espino-Sánchez, 2014). Incluso, entre los partidos políticos hay ciertas diferencias y desventajas entre unos y otros dependiendo del impacto e influencia electoral que tengan en la ciudadanía, reflejado en la cantidad de votos obtenidos (más allá de la cantidad de ciudadanos que militan en sus filas), lo que es razonable considerando que los recursos financieros no son iguales para los partidos con poco impacto electoral y no tienen tampoco las posibilidades de acceder a las mismas cantidades de tiempo en los medios masivos de comunicación.[19]

En este sentido, el reto de los candidatos independientes es darse a conocer en una sociedad por tradición partidista regida por un sistema electoral diseñado para un sistema de partidos (o "partidocracia"), en el que ambos entes (candidatos independientes y partidos políticos) se encuentran inmersos en circunstancias jurídicas, políticas y sociales distintas y en donde las reglas de los partidos se toman injustamente como referencia para las candidaturas independientes. La realidad es más desalentadora, ya que no nada más la normatividad de los partidos se toma como referencia para otorgar los derechos de los candidatos independientes, sino que, en ocasiones, sus derechos llegan a ser mucho menores y con mayores limitantes u obstáculos respecto a los de partidos políticos, lo cual evidencia una injusticia sustancial. Por ejemplo, lo anterior se demuestra con lo desproporcionado del financiamiento público que es significativamente menor que el de los partidos políticos, lo que impacta en una desequilibrada competencia electoral. Frente a lo anterior, no debe olvidarse que los derechos político-electorales de los ciudadanos (ahora fortalecidos con la posibilidad de postularse sin el apoyo de un partido político) deben tener la finalidad de que los ciudadanos cuenten con la oportunidad real de contender y también de ganar una elección, pero el sistema electoral que en la actualidad los regula parece estar diseñado para darles la oportunidad de contender después de haber obtenido con dificultades un registro oficial.

Darse a conocer en una sociedad partidista conlleva un reto de proporciones importantes en donde los medios de comunicación son de vital importancia, ya que "todas las elecciones son procesos comunicativos [...] es decir, la utilización de discursos políticos, la organización de los debates políticos y, entre otros elementos cruciales, la participación de todos los medios de comunicación" (Dorantes y Aguilar, 2014: 144). Una vez que inicia el proceso electoral los actores políticos también lo hacen con una serie de acciones para controlar la agenda mediática, para lo cual se apoyan en especialistas en la construcción de campañas (que abarca la agenda política, su contenido y la planificación general); es necesario que esas primeras acciones incluyan a un equipo profesional y a un técnico de relaciones públicas y de tecnologías e información y comunicación (TIC), cuyo objetivo es lograr la mejor imagen del candidato en los medios de comunicación, sobre todo en la televisión (Dorantes y Aguilar, 2014). Para lograrlo, se requiere de una estructura y de un financiamiento que sí tienen los partidos políticos, pero no los candidatos independientes a pesar de que existen criterios jurisdiccionales que sustentan la equidad en materia de financiamiento electoral: 
Una vez superada la etapa de registro, esas candidaturas deberán regirse por un marco normativo en relación con la obtención de recursos públicos que les permitan contender en igualdad de circunstancias respecto de sus similares postulados por algún partido político de nueva creación más allá de las diferencias evidentes o de las derivadas del texto constitucional, lo cual es acorde con la equidad que debe regir en materia de financiamiento (TEPJF, 2015: 64, 65).

De ahí el obstáculo que deben superar los candidatos independientes si es que pretenden tener una posibilidad real de obtener el triunfo en la contienda electoral y ocupar un cargo público de elección popular. Se trata de superar la ventaja abrumadora que tienen los grandes partidos políticos -incluso los pequeños-, así como las coaliciones. Pero el aspecto financiero no es el único reto (aunque tal vez sea el más impactante) que tienen los delante de sí, pues tienen la necesidad de comunicar su plan de gobierno de una manera eficaz a los potenciales votantes, lo que implica utilizar los medios de comunicación y los instrumentos mediáticos mencionados con la finalidad de ganar adeptos en un medio que ha sido partidista.

Ahora bien, esas desventajas, además de impactar en lo que se ha mencionado, tienen su efecto en el capital político que el propio candidato independiente posea o, en su caso, generar como un actor político en el interior de una sociedad, ya que también importa la carrera política que, en el caso de los candidatos partidistas, es un obstáculo fácil de superar, pero tratándose de los independientes no lo es tanto. Existe la distinción entre capital político personal y el capital delegado de una autoridad política; en este último se ve involucrado un partido político que beneficia al candidato partidista con el impulso necesario para proyectarse como posible opción para ocupar un cargo de elección popular, pero que no tiene ninguna relación (o tiene poca) con su capital político personal, como en el caso de los independientes:

El capital político personal se basa en la idea fundamental de ser 'conocido y reconocido', gracias a la posesión de notoriedad y de popularidad por tener cierto número de cualidades específicas propias [...] Por el contrario, el capital delegado de una autoridad política es el producto de una transferencia limitada y provisional de un capital detentado y controlado por una institución y sólo por ella. Por consiguiente, este capital obedece a una lógica muy particular según la cual la investidura es un acto de carácter propiamente mágico por el que la institución consagra oficialmente al candidato oficial (Alcántara-Sáez, 2016: 190).

Es tan potente el capital delegado de una autoridad política (partido político) a un candidato (partidista) que al existir una ruptura entre la persona (candidato) y la institución (partido político) se ha registrado una importante disminución de capital político personal. Por el contrario, cuando la persona reporta deficiencias en ese aspecto (capital político personal), una dosis de capital político delegado puede paliarlas (Alcántara-Sáez, 2016); de esto último carece el candidato independiente. De ahí que la militancia de los partidos políticos (aquellos ciudadanos cuya actividad está muy relacionada con los objetivos y fines de un partido político específico) obedece a ciertas causas relacionadas con los incentivos, es decir, los ciudadanos militan en los partidos políticos no solamente por su ideología, sino también por la posibilidad de socializar en el ámbito político (Katz, 2005), o incluso para la obtención de influencias y de ciertos beneficios sociales o materiales (Heidar, 2006).

Tal vez esa sea la razón por la cual los partidos políticos en la actualidad ya no precisan de un gran número de militantes; en este aspecto, hay partidos que cuentan con muy pocos miembros, lo cual habla de una suerte de decadencia partidista: "Las ofertas que tienen los electores se han ampliado, puesto que ya no sólo los partidos políticos ofrecen alternativas a los ciudadanos, sino también determinados grupos u organizaciones creando así las condiciones necesarias para que el mercado de la política sea más extenso y con mayores ofertas de elección" (Seyd y Whitely, 2004: 470); lo mismo ocurre con los candidatos independientes, quienes con su carrera política tienen además otro obstáculo por vencer: aquel que se refiere a la capitalización de su posición en la política, ya que para sostener un estatus político se requiere de mantenerse fiel al partido en el cual comenzó su carrera política (con esto podría aumentar su capital político) o cambiarse a otro partido donde le ofrezcan mejores posibilidades de progreso y donde esté más de acuerdo con los postulados ideológicos (esto podría significarle una merma de su capital político); sin embargo, en el caso de los independientes 
ninguna de opciones es viable (Alcántara-Sáez, 2016). Con todo lo anterior, el reto de darse a conocer en una sociedad partidista desemboca necesariamente en la transformación del paradigma democrático mexicano, ya que esos obstáculos y vicisitudes a los que se enfrenta el candidato independiente se pueden sortear sólo si se comienza a dar una verdadera apertura a un nuevo modelo político-electoral que implica una transformación de esa magnitud.

\section{Transformar el paradigma democrático mexicano}

Uno de los aspectos de suma importancia para la transformación del paradigma en México es la participación, ya que trae beneficios necesarios en toda democracia: proporciona una progresiva adecuación del funcionamiento de las instituciones, rompe la apatía y desconfianza ciudadana, ofrece a los representantes algunas herramientas para evaluar y mejorar la gestión de los asuntos públicos al permitir a la ciudadanía reconquistar y recuperar el espacio público, así como también que la política se socialice para reforzar las decisiones a adoptar o ya adoptadas, pero para lograr que el ciudadano ejerza un nivel adecuado con lo anterior es necesario que se construyan e implementen mecanismos y así crear las condiciones para una verdadera participación donde los ciudadanos se involucren en la cosa pública (Pastor-Seller, 2015). Tal participación, tratándose de la actividad partidista, se traduce en los militantes con los que cuentan los partidos; en este aspecto, se ha planteado la pregunta: ¿cuál era la función de los militantes cuando los partidos no tenían acceso a los medios de comunicación ni contaban con financiamiento para difundir su ideología y realizar sus campañas? La respuesta es que tenían dos funciones: la militancia llevaba de puerta en puerta las propuestas partidistas y también contribuían financieramente a su organización (Muñoz Armenta et al., 2013). Trasladando lo anterior a la situación por la que atraviesan los candidatos independientes, cabría preguntar cuánta necesidad tienen de contar con militantes, es decir, con ciudadanos participativos cuya actividad sirva para reforzar los fines de la democracia mencionados.

La fortaleza de los partidos políticos, de acuerdo con algunos estudios (Poiré, 1999; Moreno, 2003, 2009; Klesner, 2004; Flores-Macías, 2009; Somuano Ventura, 2014), está asociada de forma directa con la lealtad del voto ciudadano, es decir, que con frecuencia no es el capital político personal del candidato partidista, sino aquel cuya fuente es precisamente el partido político, ya que entre más fuerte es la identificación partidista de los votantes con el partido, hay una mayor probabilidad de que voten por los candidatos del partido con el cual se identifican. Para lograr que se transforme el paradigma democrático mexicano es necesaria (hasta cierto punto) una ruptura con el sistema partidista deficiente que obstaculiza a la democracia y ralentiza sus prácticas y sus valores, lo cual implica, de forma primordial, la posibilidad real de que cualquier ciudadano pueda ser votado sin partido político bajo el ejercicio y aplicación de instrumentos jurídicos eficientes para lograrlo. Esa posibilidad real es una circunstancia que también se ve afectada no sólo por los "activos individuales" (Alcántara-Sáez, 2016) con los que cuenta el político al inicio de su carrera política, sino también por los mecanismos institucionales (con frecuencia partidistas, aunque no siempre); en esencia, los políticos cuentan con un capital político que puede proceder de cinco fuentes:

La primera es estrictamente política y está derivada del proceso de investidura que le otorga su adscripción a una formación política concreta, cuyo interés fundamental radica en reclutar a personal para sus fines [...] La segunda proviene del nivel de formación adquirida y posiblemente completada con cierta experiencia profesional en instancias laborales [...] Ellas terminan dotándole de una expertise, técnica que le abre la puerta del mundo de la política por su funcionalidad [...] La tercera se deriva de la posesión de altas cotas de popularidad provenientes de la práctica de una actividad que tenga una amplia exposición social [...] La cuarta procede del legado familiar como consecuencia de pertenecer a una saga con antecedentes y experiencia en la vida política que proveen a la persona candidata de símbolos, contactos y redes [...] La última se deriva de la posesión de una renta económica suficiente que permite afrontar los costos de entrada, básicamente de la campaña electoral" (Alcántara-Sáez, 2016: 194-195). 
Como se ve, el capital político de los candidatos proviene por lo general de fuentes estrictamente partidistas, aunque no siempre, lo que lleva a considerar que, en el caso de los independientes, el problema se agudiza y se ven obligados a subsanar los faltantes de capital político por otros medios. Esa situación se agrava con una normatividad jurídica diseñada para partidos políticos en un medio político y social que por décadas ha sido partidista. Ese es otro de los retos a los que se enfrentan los candidatos independientes: transformar el paradigma democrático mexicano en el que prevalece un sistema de partidos auspiciado por un sistema jurídico ad hoc; por lo tanto, se hace necesario que el sistema electoral equilibre de alguna manera esos faltantes de capital de los ciudadanos que pretendan postularse como candidatos independientes. Una circunstancia contrastante con lo anterior es que en los últimos tiempos el espectro de amplitud de los ciudadanos que militan en los partidos políticos ha ido en declive a causa de una disminución en la identidad partidista (Katz, 2005). Hay quien considera que "el aumento en el número de apartidistas y la disminución de los electores con identificación partidista fuerte se traduce en una ampliación del electorado disponible, hacia el cual los partidos y sus candidatos pueden orientar sus estrategias y tácticas de maximización de votos" (Díaz-Jiménez et al., 2015). Transformar ese paradigma democrático requiere comprender y aceptar que las candidaturas independientes constituyen (o pueden constituir) el basamento sostenedor de la democracia en países con ese régimen, ya que se manifiesta y se desenvuelve al amparo y auspicio de la soberanía como uno de los elementos legitimadores de la democracia.

La regulación e implementación de las candidaturas independientes no debe ser en exclusivo un medio paliativo a las necesidades emergentes o a los reclamos legítimos de la ciudadanía, sino que debe ser un remedio de fondo para la consolidación real de la democracia en México. Más que ocupar el poder, los candidatos independientes tienen el reto hacer presión para evidenciar alternativas democráticas viables y con esto lograr que la práctica de la política se reconfigure. Así, cuando las candidaturas independientes se constituyan en una competencia real e inminente contra los partidos políticos en busca de una posición gubernamental, éstos se verán forzados a mutar y a mejorar en diversos aspectos, por ejemplo, en cuanto a la selección de sus candidatos. [20] También, la necesidad de que los candidatos partidistas cambien y mejoren, por ejemplo, en cuanto a sus propuestas, ya que el capital político con el que cuentan (aunque provenga del partido que lo postuló) competirá directamente contra el del candidato independiente. En este aspecto surge la necesidad de comunicar su plan de gobierno a los ciudadanos votantes e implica la necesidad de usar de manera adecuada los medios de comunicación y las estrategias mediáticas, como ya se vio, pero también en cuanto al contenido de lo que se comunica a través de esas estrategias mediáticas; es decir, además de las desventajas que tienen los candidatos independientes frente a los partidos políticos en cuanto al acceso a esos instrumentos, está también el aspecto de fondo que refiere al contenido de esos comunicados, lo cual tiene que ver con la agenda temática:

A la agenda temática se le adscriben temas generales, más que específicos, básicamente de carácter económico y social [...] es más sencillo consensuar entre el electorado un problema más abstracto, aunque real: combate a la pobreza o a la inseguridad, saneamiento del medio ambiente [...], que especificar la solución de los mismos o poner a debate diversas alternativas de solución. Otra razón [...] es que una propuesta concreta de solución que puede beneficiar a un segmento del electorado, al mismo tiempo puede perjudicar a otro; tal vez más relevante (Dorantes y Aguilar, 2014: 157).

Las agendas temáticas se construyen cuando se pregunta a los electores sobre los problemas más emergentes (a través de una encuesta o algún otro instrumento similar), después se elaboran las categorías que definan el problema y no tanto sus causas, al final se proponen alternativas generales de solución; todo lo anterior debe sustentarse metodológicamente dándole mayor importancia a los efectos que a las causas; por ello, es necesario crear una imagen positiva y mediática del candidato que resalte sus atributos personales (Dorantes y Aguilar, 2014). Así, los ciudadanos que más se requieren en una sociedad democrática son aquellos que 
sepan y quieran practicar sus derechos y libertades para que no se queden en el nivel de un pronunciamiento agradable y utópico, sino ser efectivamente parte de la vida pública concurriendo en la discusión pública y alejándose de la demagogia (Fernández-Santillán, 2016). En este punto surge la pregunta sobre la mejor posición respecto a la agenda política:

Por un lado, la que considera que debe darse mayor peso a los temas sociales más sentidos por el electorado, si bien los menos controversiales; por el otro, la que juzga que el mayor peso específico deben tenerlo los atributos personales del candidato. Una postura de medio camino considera que la agenda de campaña debe configurarse mediante un equilibrio entre temas y atributos (Dorantes y Aguilar, 2014: 154).

No nada más los atributos de las personas o de los candidatos son un tema de relevancia, otro de los grandes retos de los candidatos independientes es abatir la desconfianza de la ciudadanía, ya que existe toda una historia de sucesos en los que la corrupción, la violencia y, en general, la ineficacia gubernamental, han generado un hartazgo hacia el sector gubernamental y hacia los partidos políticos; esta situación ha desembocado en una apatía ciudadana y ha disminuido los índices de participación. Por ello, hay quien considera que los sistemas de partidos políticos reducen las relaciones políticas a un conformismo meramente exterior debilitando y marchitando su objetivo relacionado con los asuntos públicos, es decir, el formalismo político derivado de ese sistema de partidos ha disminuido el poder de intimidación social y le ha impedido consolidarse (Ostrogorski, 2008). En la actualidad los reclamos por las deficiencias de los partidos políticos son una constante que se refuerza con la demanda generalizada de que los ciudadanos sean incluidos en el ejercicio gubernamental por medio de la participación política, donde destaca la figura de la candidatura independiente como una solución a los problemas de la representación política y del descrédito del ámbito político (Salazar Carrión, 2014). Así, un cambio efectivo en todos esos aspectos significaría en realidad una verdadera transformación del actual paradigma democrático mexicano. En ese sentido, algunos otros estudios ya han abordado la cuestión de la siguiente manera:

“¿Cómo las formas existentes de participación política se oponen o armonizan con los fundamentos político-legales de la condición ciudadana en un Estado democrático? En el entendido de que los mecanismos originalmente diseñados para la expresión política de los ciudadanos estaban pensados para un contexto económico, político y social que actualmente difiere del actual debido al peso preponderante en las decisiones políticas nacionales que están ejerciendo entidades político-económicas trasnacionales" (Ordóñez Huerta, 2018: 163).

Las candidaturas independientes son una de las formas más acabadas de la participación política en democracia; sin embargo, no armoniza con un paradigma democrático, político y social que fue pensado y diseñado para un sistema partidista. De ahí la necesidad de una transformación a ese modelo democrático-electoral.

\section{Prospectiva}

En México, tal como lo ha enseñado su historia reciente, las reformas electorales son casi por completo consecuencia de lo acontecido en cada una de sus elecciones. Con ello, y una vez revisada la elección de 2018, se pueden responder las preguntas: ¿ hacia dónde se encaminan las candidaturas independientes en México ? y ¿qué es lo que se vislumbra hacia el futuro? Para esto debemos tomar en cuenta la regulación (tanto constitucional como legal) de las candidaturas independientes y no dejar de lado que el principal reto es darse a conocer en una sociedad partidista con la finalidad última de transformar el paradigma democrático mexicano. La historia nos ha enseñado que gradualmente las normas jurídicas se han ido ajustando a las nuevas realidades haciendo más democrático el sistema electoral, por lo que, en general, se puede observar la tendencia de que el Estado mexicano ajuste su sistema normativo electoral para reforzar las posibilidades de participación que deben tener 
todos los ciudadanos y así evitar que quienes posean potencial para gobernar sientan el desánimo aun antes de intentar postularse de manera independiente o, peor aún, que sean obstaculizados por el sistema jurídico o por los órganos de gobiernos.

La tendencia es que el sistema de elecciones en México se irá haciendo cada vez más congruente con las nuevas realidades y necesidades respecto a las candidaturas independientes, en específico en cuanto a los mecanismos de participación ciudadana, los cuales se irán reforzando para que se permita que todos los ciudadanos estén en la posibilidad de ejercer su derecho de voto pasivo y que solamente sean circunstancias diversas a las jurídicas u organizacionales las que propicien la decisión ciudadana de no participación.

No es absurdo prever la creación de órganos de gobierno (tal vez dependientes de la autoridad administrativa electoral, como los institutos electorales o, a nivel federal, como el Instituto Nacional Electoral), cuya función preponderante sea alentar la participación de los ciudadanos a postularse como candidatos independientes. Todo ello fundado en una adecuada regulación legal en los ámbitos municipal, estatal y federal: tal vez con la creación de comités técnicos integrados por autoridades electorales y por ciudadanos, a la manera de la integración de las mesas directivas de casilla, lo cual estaría satisfaciendo una necesidad urgente de ciudadanización en cuanto a la postulación de candidaturas independientes; serían una suerte de órganos de participación cuya función sea de asesoría y consulta relacionada con la postulación de candidaturas independientes, entre otros mecanismos. Desde luego, para lograrlo, es necesario que los mecanismos mencionados sean diseñados de manera tal que la ciudadanía se sienta motivada a participar como candidato independiente y no que tenga la sensación de rechazo a causa de los múltiples y variados obstáculos constitucionales, legales, políticos y sociales (incluso económicos) que tendría que remontar para poder postularse, tal como sucede en la actualidad.

Cada vez más, los mecanismos destinados a que los ciudadanos sean escuchados, respetados y reconocidos como potenciales candidatos a cargos de elección popular, serán una realidad con el consecuente beneficio de que la actual posibilidad -restringida y obstaculizada- de postularse sin partido político se convertirá en una situación factible y concreta gracias a mecanismos de participación horizontal, y no sólo vertical. Todo esto traerá como beneficio que las posibilidades reales de participación como candidatos independientes lleguen a todas las posiciones sociales y territoriales del país, con lo cual se podría evitar los privilegios de ciudadanos "famosos" en detrimento de aquellos con cierto grado de anonimato (pero que también tienen potencial de ser valiosos como candidatos y hasta como detentadores de los cargos públicos) o evitar, en el otro extremo, a los muy "expertos" cuya experiencia no garantiza una moral pública adecuada y, lo que podría ser peor, aquellos ciudadanos que gozan de una posición económica elevada en detrimento de quienes no cuentan con suficiente capital para gastar/invertir en las campañas o en la proyección de su propia imagen y que por esa razón financiera no pueden postularse como candidatos independientes.

Con todo esto, no es desatinado prever que en las próximas elecciones sean un mayor número de ciudadanos los que se postulen de manera independiente y que los partidos políticos, como consecuencia de esto, vayan reforzando sus mecanismos para evitar perder cada vez más la credibilidad de la que antaño gozaban. Esto, aunado al hartazgo de la ciudadanía respecto a la actuación de los partidos políticos, será un aspecto detonante por el que las candidaturas independientes tendrán cada vez mayor fuerza política. La finalidad es que el ciudadano pueda ejercer realmente el poder público que tiene conferido por virtud de la soberanía popular: es empoderar a los ciudadanos, es devolverles la soberanía que hasta el momento han tenido de manera parcial. La posibilidad real de que puedan postularse como candidatos independientes o acceder a un cargo de elección popular es uno de los retos más grandes que tiene el sistema democrático mexicano. Una vez superado lo anterior, se podría configurar uno de los elementos esenciales de la democracia y para su ejercicio/transición de/hacia la misma en un nivel territorial que no distinga zonas geográficas, niveles sociales, ámbitos económicos, posiciones políticas, etc., y dará eficacia y eficiencia a la tan anhelada democratización para que ahora sí se pueda hablar de una soberanía como un verdadero poder del pueblo. 


\section{Conclusiones}

La existencia de diversos obstáculos para las candidaturas independientes es una de las causas por las que se vuelve complejo acceder al cargo de elección popular de presidente de la República en México por tratarse de una sociedad que tradicionalmente ha sido partidista. Para superar esos retos y fortalecer la democracia en México en el futuro inmediato, se debe considerar con seriedad la implementación de algunas medidas jurídicas que inciden en lo sustantivo y en lo orgánico: $a$ ) mayor flexibilidad en cuanto a los requisitos constitucionales y legales requeridos para la postulación de las candidaturas independientes; $b$ ) la creación de órganos de gobierno cuyas funciones y atribuciones sean las necesarias para impulsar la participación ciudadana en cuanto a las candidaturas independientes; $c$ ) legislar las reglas necesarias y suficientes para que se establezcan con claridad los derechos y obligaciones de los ciudadanos en cuanto a su derecho de voto pasivo, así como los procedimientos mediante los cuales esto sea posible; $d$ ) que esa legislación contemple mecanismos para universalizar los derechos ciudadanos de postularse como candidatos independientes y que no siga siendo una posibilidad únicamente para aquellos agraciados por el sistema jurídico y político; $e$ ) que haya una descentralización y desconcentración en cuanto a la estructura gubernamental definida para todo ello con la finalidad de que las posibilidades jurídicas se conviertan en posibilidades reales para los ciudadanos que habitan incluso más allá de los centros gubernamentales; $f$ ) educar en cuanto a la representatividad para que el modelo partidista no sea considerado como la panacea inalcanzable para poder participar/acceder a cargos de elección popular e ir optando poco a poco por los sistemas híbridos o combinados en los que intervenga el sistema por sorteo; $g$ ) educar a la ciudadanía en cuanto a participación política en un sistema democrático, lo que implica aspectos de culturización, politización y planificación adecuada de los procesos de participación de los ciudadanos como candidatos independientes; por último, $h$ ) implementar estrategias de mayor impacto y eficacia que ayuden a reducir la brecha entre un cargo público visto como un puesto inalcanzable para los ciudadanos apartidistas y que los mecanismos de participación partidista/asociativa sean compatibles/proporcionales con la participación directa/independiente.

\section{Agradecimientos}

Agradezco a los árbitros por las interesantes e importantes observaciones y sugerencias que sirvieron para el mejoramiento de este trabajo.

\section{REFERENCIAS}

Alcántara-Sáez, M. (2016). La carrera política y el capital político. Convergencia. Revista de Ciencias Sociales, 73. https://doi.org/10.29101/crcs.v0i73.4243.

Becerra, R., Salazar, P. y Woldenberg, J. (2000). La mecánica del cambio político en México: elecciones, partidos y reformas. México: Cal y Arena.

CorteIDH (Corte Interamericana de Derechos Humanos). (2008). Caso Castañeda Gutman vs Estados Unidos Mexicanos. Sentencia del 6 de agosto de 2008. Disponible en http://www.corteidh.or.cr/docs/casos/ articulos/seriec_184_esp.pdf

DO (Diario Oficial). (1977). Órgano del Gobierno Constitucional de los Estados Unidos Mexicanos. Tomo CCCXLV. Número 26. México.

DOF (Diario Oficial de la Federación). (2007). Órgano del Gobierno Constitucional de los Estados Unidos Mexicanos. Tomo DCL. Número 9. México. 
DOF (Diario Oficial de la Federación). (2012). Órgano del Gobierno Constitucional de los Estados Unidos Mexicanos. Tomo DCCVII. Número 7. México.

DOF (Diario Oficial de la Federación). (2013). Órgano del Gobierno Constitucional de los Estados Unidos Mexicanos. Tomo DCCXXIII. Número 21. México.

Díaz-Jiménez, O. y Vivero-Ávila, I. (2015). Las dimensiones de la competencia en el sistema de partidos mexicano (1979-2012). Convergencia. Revista de Ciencias Sociales, 68. https://doi.org/10.29101/crcs.v0i68.2950.

Dorantes y Aguilar, G. L. (2014). Procesos electorales y democracia: la construcción de una agenda de campaña política. Convergencia. Revista de Ciencias Sociales, 64. Disponible en https://convergencia.uaemex.mx/ article/view/991.

Espino-Sánchez, G. (2014). La política en internet, ¿de la mediatización a la convergencia digital? Convergencia. Revista de Ciencias Sociales, 65. Disponible en https://convergencia.uaemex.mx/article/view/998.

Fernández-Santillán, J. (2016). Isócrates y los orígenes de la educación cívica. Actualidad de un pensador clásico. Convergencia. Revista de Ciencias Sociales, 71. https://doi.org/10.29101/crcs.v0i71.3989

Flores-Macías, F. (2009). Electoral Volatility in 2006. In Jorge I. Domínguez, Chappell H. Lawson \&Alejandro Moreno [comps.], Consolidating Mexico's Democracy: The 2006 Presidential Campaign in Comparative Perspective. Baltimore: Johns Hopkins University Press.

Greene, K. F. (2007). Why dominantparties lose: Mexico's democratization in comparativeperspective. Cambridge: Cambridge University Press.

Heidar, K. (2006). Party membership and participation. In Richard Katz y William J. Crotty (eds.), Handbook of party politics. London: Sage Publications.

Heras Gómez, L. y Díaz Jiménez, O. F. (2017). Las redes sociales en las campañas de los candidatos a diputados locales del PRI, el PAN y el PRD en las elecciones de 2015 en el Estado de México. Apuntes Electorales: revista del instituto electoral del estado de México, 16(57).

INE (Instituto Nacional Electoral). (2018a). Cómputos distritales 2018. Elecciones federales. Consultado en https://computos2018.ine.mx/\#/presidencia/nacional/1/1/1/1.

INE(Instituto Nacional Electoral).(2018b).Estadisticas listanominaly padrón electoral. Disponible en_http://portalanterior.ine.mx/archivos3/portal/historico/contenido/Estadisticas_Lista_Nominal_y_Padron_Electoral/.

Katz, R. (2005). The internal life of parties, en Richard Luther et al. (ed.), Political Parties in the New Europe. New York: Oxford University.

Klesner, J. L. (2004). The structure of the mexican electorate: Social, attitudinal, and partisan bases of Vicente Fox's Victory, en Jorge I. Domínguez y Chappell Lawson [comps.], Mexico's pivotal democratic election: Candidates, voters, and the presidential campaign of 2000. Stanford: Stanford University Press.

LEGIPE (Ley General de Instituciones y Procedimientos Electorales). (2014). Cámara de Diputados del H. Congreso de la Unión, 23 de mayo de 2014.

LGPP (Ley General de Partidos Políticos). (2014). Cámara de Diputados del H. Congreso de la Unión, 23 de mayo de 2014.

Lizcano Fernández, F. (2012). Democracia directa y democracia representativa. Convergencia. Revista de Ciencias Sociales, 60. Disponible en https://convergencia.uaemex.mx/article/view/1073

Martínez González, V.H. (2016). Partido cartel. Una revisión crítica del concepto. Foro Internacional, 56(4). Disponible en http://www.scielo.org.mx/scielo.php?script=sci_arttext\&pid=S0185-013X2016000401053\#fn1

Méndez de Hoyos, I. (2006). Transición a la democracia en México: competencia partidista y reformas electorales 1977-2003. México: Fontamara. 
Michels, R. (2008). Los partidos politicos: un estudio sociológico de las tendencias oligárquicas de la democracia moderna. Buenos Aires: Amorrortu.

Molinar, J. (1991). El tiempo de la legitimidad: elecciones, autoritarismo y democracia en México. México: Cal y Arena.

Molinar, J. (1996). Changing the balance of power in a hegemonic party system: The case of Mexico, In A. Lijphart \& C. H. Waisman (comps.), Institutional Design in New Democracies: Eastern Europe and Latin America. Boulder: Westview.

Moreno, A. (2003). El votante mexicano: democracia, actitudes politicas y conducta electoral. México: Fondo de Cultura Económica.

Moreno, A. (2009). La decisión electoral: votantes, partidos y democracia en México. México: Miguel Ángel Porrúa.

Muñoz Armenta, A., Heras-Gómez, L. y Pulido-Gómez, A. (2013). Una aproximación a la militancia partidista en México: el caso de los partidos emergentes. Convergencia. Revista de Ciencias Sociales, 63. Disponible https://convergencia.uaemex.mx/article/view/1025.

Norris, P. (1997). Electoral change in Britain since 1945. Oxford: Blackwell.

Ordóñez Huerta, M. (2018). Enfoques teóricos sobre la participación política ciudadana y la democracia moderna. Ius Comitiälis, 1(1), 161-174. Disponible en https://iuscomitialis.uaemex.mx/article/ view/10715.

Ostrogorski, M. (2008). La democracia y los partidos politicos. Madrid: Trotta.

Pastor-Seller, E. (2015). Oportunidades de participación en las políticas de servicios sociales municipales en España. Convergencia. Revista de Ciencias Sociales, 68. https://doi.org/10.29101/crcs.v0i68.2959.

Poiré, A. (1999). Retrospective voting, partisanship, and loyalty in presidential elections: 1994, In Jorge I. Domínguez y Alejandro Poiré [comps.], Toward Mexico's democratization: Parties, Campaigns, elections, and public opinion. London: Routledge.

Salazar Carrión, L. (coord.) (2014). ¿Democracia o posdemocracia? Problemas de la representación política en las democracias contemporáneas. México: Fontamara.

Schumpeter, J. A. (1996). Capitalismo, socialismo y democracia. Barcelona: Ediciones Folio.

Seyd, P. \& Whitely, P. (2004). British party members. Party Politics, 10(4).

Somuano Ventura, M. F. (2014). Las identidades partidistas de los mexicanos y la elección de 2012, en Gustavo Meixueiro y Alejandro Moreno [comps.], El comportamiento electoral mexicano en las elecciones de 2012. México: Centro de Estudios Sociales y de Opinión Pública/Cámara de Diputados.

TEPJF (Tribunal Electoral del Poder Judicial de la Federación). (2015). Candidaturas independientes. Igualdad respecto al financiamiento público de los candidatos postulados, en relación con un partido político de nueva creación. Gaceta de jurisprudencia y tesis en materia electoral, 8(17). Tesis LIII/2015. Quinta época.

Valdés Zurita, L. (1995). El efecto mecánico de la fórmula electoral mexicana: 1964-1991. Polis, 94.

\section{Notas}

[1] Originalmente, la Constitución Política de los Estados Unidos Mexicanos, en su artículo 41, no establecía nada acerca de los partidos políticos; sin embargo, en su primera reforma se adicionó el siguiente texto: "Los partidos políticos son entidades de interés público [...] tienen como fin promover la participación del pueblo en la vida democrática, contribuir a la integración de la representación nacional, como organizaciones de ciudadanos, hacer posible el acceso de éstos al ejercicio del poder público" (DO, 1977). También, en 2007 se agregó el siguiente texto su artículo 116: "IV. Las constituciones y leyes de los estados en 
materia electoral garantizarán que: [...] e) Los partidos políticos [...] tengan reconocido el derecho exclusivo para solicitar el registro de candidatos a cargos de elección popular" (DOF, 2007), lo que expresamente les daba a los partidos políticos el monopolio para postular candidatos a cargos de elección popular, con la excepción de ciertas atribuciones que fueron otorgadas a las comunidades indígenas. No fue sino hasta la reforma del artículo 35 en 2012, cuya fracción II quedó de la siguiente manera: "Son derechos del ciudadano: ... II. [...] El derecho de solicitar el registro de candidatos ante la autoridad electoral corresponde a los partidos políticos, así como a los ciudadanos que soliciten su registro de manera independiente y cumplan con los requisitos, condiciones y términos que determine la legislación” (DOF, 2012); lo anterior fue congruente con otra reforma al artículo 116 en 2013, donde se estableció que "los poderes de los Estados se organizarán conforme a la Constitución de cada uno de ellos, con sujeción a las siguientes normas: [...] IV. Las Constituciones y leyes de los Estados en materia electoral garantizarán que: [...] o) Se fijen las bases y requisitos para que en las elecciones los ciudadanos soliciten su registro como candidatos para poder ser votados en forma independiente a todos los cargos de elección popular, en los términos del artículo 35 de esta Constitución” (DOF, 2013). De esta manera, formalmente quedó establecida la figura del candidato independiente en México.

[2] Como ejemplo se puede citar el caso Castañeda Gutman vs. México (CorteIDH, 2008), referido a la responsabilidad internacional de México por la inexistencia de un recurso adecuado y efectivo para solucionar el impedimento de Jorge Castañeda Gutman para registrarse como candidato independiente a la presidencia de la República; la Corte Interamericana de Derechos Humanos declaró que el Estado Mexicano violó su derecho a la protección judicial, aunque, respecto a su derecho político a ser elegido, declaró que no hubo violación.

[3] Sin embargo, en las recientes elecciones federales del $1^{\circ}$ de julio de 2018 en México hubo una manifestación de rechazo (casi de repudio) por parte de la población mexicana, ya que el partido político de izquierda Morena (Movimiento Regeneración Nacional) obtuvo más de 53\% de la votación para su candidato a la presidencia de la República, Andrés Manuel López Obrador, y tuvo un efecto electoral en cascada en la mayoría de los estados en los que hubo elección y también en los municipios (INE, 2018a).

[4] Aunado a un modelo de gobierno para la administración de las elecciones donde el Poder Ejecutivo las organizaba y las validaba (Molinar, 1991, 1996; Valdés Zurita, 1995; Becerra et al., 2000; Méndez de Hoyos, 2006).

[5] Específicamente aquellas que pretenden ocupar el cargo de presidente de la República.

[6] Aunque desde 2015 ya era posible postularse de manera independiente para cargos estatales. El primer candidato independiente ganador de una elección para gobernador (Estado de Nuevo León) es Jaime Heliodoro Rodríguez Calderón, el Bronco.

[7] Caracterizados por el poco o, en ocasiones, nulo respeto a las leyes o a los derechos políticos.

[8] Primero al elegir a esos representantes y después por medio de ellos.

[9] Al respecto, se puede considerar un interesante artículo sobre la revisión crítica del concepto de "partido cartel”, en el que se analizan los trabajos de Katz y Mair en relación con el hecho de que los partidos, al padecer el descenso de las cuotas de sus afiliados, comenzaron a depender del financiamiento público, lo cual sería el detonante de los partidos cartel (Martínez González, 2016).

[10] El artículo $3^{\circ}$, fracción c) de la Ley General de Instituciones y Procedimientos Electorales, define al candidato independiente como "el ciudadano que obtenga por parte de la autoridad electoral el acuerdo de registro, habiendo cumplido los requisitos que para tal efecto establece la presente ley" (LEGIPE, 2014).

[11] Establece en la fracción II, de su artículo 35 (DOF, 2012), que es derecho del ciudadano: "Poder ser votado para todos los cargos de elección popular, teniendo las calidades que establezca la ley. El derecho de solicitar el registro de candidatos ante la autoridad electoral corresponde a los partidos políticos, así como a los ciudadanos que soliciten su registro de manera independiente y cumplan con los requisitos, condiciones y términos que determine la legislación”.

[12] Sin omitir, desde luego, los criterios jurisdiccionales y la jurisprudencia.

[13] Independientemente de que existen otras normas jurídicas en materia electoral incluidas en tratados o convenciones internacionales (de los cuales México es parte), así como criterios y jurisprudencia internacional sobre la materia.

[14] Este documento contiene a todos aquellos ciudadanos que solicitaron su inscripción al padrón y cuentan ya con credencial para votar vigente; por tanto, pueden emitir su voto en la jornada electoral siguiente (INE, 2018b).

[15] Es la base de datos en la que se encuentra la información básica de los ciudadanos que solicitaron su inscripción para obtener su credencial para votar.

[16] Esto tomando en cuenta que la lista nominal considerada para el proceso electoral federal de 2018 incluyó 86659234 ciudadanos, es decir, 705522 ciudadanos sumados a los del corte del 16 de junio de 2017.

[17] Desde luego, este resultado fue obtenido con base en los datos estadísticos presentados, los cuales varían con el paso del 
tiempo, ya que los movimientos de inscripción al padrón electoral y de integración de la lista nominal de electores son continuos y permanentes. Esta información solamente es ilustrativa de la potencial diferencia respecto al requisito cuantitativo de los apoyos necesarios para el registro de candidaturas independientes.

[18] Llamados topes en el sistema electoral mexicano.

[19] La legislación establece que los candidatos independientes (cuando ya han conseguido su registro) se harán acreedores a un financiamiento público para gastos de campaña, para lo cual todos los candidatos independientes en conjunto serán considerados como un partido político de nueva creación y el financiamiento que le correspondería a ese partido será distribuido entre todos los candidatos independientes al cargo de presidente de la República a razón de un 33\% de forma igualitaria para todos ellos. Tratándose del acceso a la radio y televisión, los candidatos independientes accederán en conjunto como si se tratara de un partido de nuevo registro y únicamente tendrán acceso a la radio y televisión en campaña electoral. Respecto a las franquicias postales, cada candidato independiente será considerado como un partido de nuevo registro para la distribución de 4\% de la franquicia postal y no tendrán derecho al uso de franquicias telegráficas (artículos 407, 408, 412, 421, 422 LEGIPE, 2014).

[20] Los partidos políticos no han tenido la necesidad de mejorar en cuanto a algunos de sus procedimientos, como la selección de candidatos (a pesar de que la ley los obliga a que esos procedimientos sean democráticos), y esto ha causado un "debilitamiento de las lealtades afectivas habituales y estables hacia los partidos entre el electorado", fenómeno conceptualizado como "desalineamiento" (Norris, 1997: 86); esto significa que muchos de los ciudadanos comienzan a perder el sentimiento que los liga con los partidos. Este fenómeno se pudo constatar en las recientes elecciones federales, estatales y municipales celebradas en México el pasado $1^{\circ}$ de julio de 2018, donde el candidato ganador de la elección presidencial obtuvo casi 53\% de la votación, lo que significa que ni siquiera los otros candidatos juntos (del PRI, PAN, PRD y un independiente) podrían haber igualado ese porcentaje.

\section{BY-NC-ND}

